\title{
Guidelines and tools to prevent risks in valleys downstream from large dam-reservoir systems: a review
}

\author{
J. Simão Antunes do Carmo \\ University of Coimbra, Department of Civil Engineering, \\ Polo II of the University, Portugal
}

\begin{abstract}
An integrated dam-reservoir-valley risk management system can be conceptually composed of two parts: the risk assessment process, in which an approximate quantitative risk analysis and evaluation is made, and the risk mitigation process, in which actions to reduce the risk are identified and implemented. This study presents a philosophy of dam-reservoir and valley system safety, taking into account both principles of preventing accidents and minimizing damage.

The mitigation of possible hazards due to a dam accident or incident must consider the uncertainties of predicted effects on a dam due to input parameters and variables of a stochastic nature. In this context, a methodology is proposed to calculate uncertainties of predicted loads on dams due to horizontal ground motions caused by earthquakes and to waves generated by landslides into reservoirs, which become functions of random variables. A methodology is also proposed for management of accidents combining risk management and civil protection.

Keywords: dam-reservoir and valley systems, integrated management, earthquakes, landslides, hazard and risk assessment, risk mitigation.
\end{abstract}

\section{Introduction}

Dams are built for many purposes: water storage for potable water supply, livestock water supply, irrigation, fire-fighting, flood control, recreation, navigation, hydroelectric power or simply to contain mine tailings. Dams may be multifunctional, serving two or more of these purposes. However, large 
reservoirs constructed near urban areas have a high potential risk for life and property downstream.

The total risk for dam structures depends on two main factors:

i. Natural hazards such as floods, earthquakes and landslides;

ii. Human behaviour, errors, simple mistakes and operational mismanagement.

Improving the understanding of realistic risks and possible reasons for dam failure is an essential first step in any overall effort to improve dam safety and risk management, as well as to preserve the benefits of dam ownership [1]. There are many complex reasons for a dam failure - both structural and non-structural. Many sources of failure can be traced to decisions made during the design and construction process, including poor quality of construction and construction materials, and to inadequate maintenance or operational mismanagement.

Any of these factors may lead to the total or partial destruction of a dam, and to the formation of a devastating flood wave. An exhaustive study presented in [2] lists the main causes of dam failure:

- 37\% ( $\pm 8 \%$ ) foundation problems (seepage, piping, excess pore pressure, fault movement, settlement);

- $30 \%( \pm 5 \%)$ floods exceeding spillway capacity;

- $23 \%( \pm 12 \%)$ improper design and construction, inferior quality of materials, acts of war, faults in operation and maintenance;

- $10 \%( \pm 5 \%)$ slides (earth, rock, glacier, avalanches).

All these causes can be a potential threat to the downstream-valley system, which includes the river, land, buildings, environmental and heritage assets, and people, along with their social organisation and infrastructures.

In general, a complete picture of the whole situation is not available, i.e., the information available is not enough. The situation is too complex to come up with an unequivocal answer. Such risk quantification is subjective, which means that someone might disagree with our evaluation. Our subjective assessments of risk are likely to change when we get more information on the situation.

An effective mitigation of possible hazards due to a dam accident or incident clearly requires integrated risk management, which should include both the damreservoir risk control and the valley system protection. The success of this integrated methodology relies on having both a great deal of information, including different types of maps and sets of physical and computational simulations, and the use of available technologies, like GIS and databases. Suggested procedure is as follows:

1. Scope definition and hazard identification (banks-reservoir system)

- information obtained locally and from old maps of the area and past earthquake records;

- mapping the area, through the construction of inventory, susceptibility, hazard and, finally, risk maps;

- physical characterization of potential aerial and submerged landslides.

2. Information needed for hazards and internal risk analysis (dam-reservoir system) 
- computer modelling of dynamic pressure fields on a dam under the influence of earthquakes, considering the most probable scenarios and uncertainty analysis;

- computer modelling of the formation and propagation of waves caused by potential landslides, considering the most probable scenarios and uncertainty analysis;

- computer modelling of the impact of waves caused by the most probable scenarios of potential landslides on a dam/reservoir banks.

3. Information needed for consequence analysis (dam-valley system)

- computer modelling of dam breaches and dam-break floods, considering the most probable scenarios and uncertainty analysis.

4. External risk analysis (valley system)

- risk analysis based on inundation mapping and socio-economic land-use as well as on public risk perception and response.

\section{Mitigation measures (valley system)}

- emergency planning, including evacuation planning and public information and training.

Therefore, several conceptual and computational models must be developed in the overall context of risk analysis, and validated with physical results and/or field data.

\section{Uncertainty modelling}

Deterministic models conceived to calculate earthquake hydrodynamic pressures on dams, and waves generated by landslides into reservoirs, include various mechanisms that are described by differential equations relating several parameters or variables. The values of these parameters have associated uncertainties, and the geotechnical variables are stochastic in nature as well as including earthquake accelerations.

The deterministic models represent neither the uncertainty of the parameters nor the variability of the environmental processes. If these values are the best estimates of the input variables, as given by their expected values, the model will predict the expected or mean output. To increase the amount of information provided by these models it is necessary to represent the variability that is associated with various parameters. For this, the uncertain parameters and the variables of stochastic behaviour can be modelled by random variables. In the cases we are dealing with, the pressure diagrams on a dam and the waves generated by landslides into reservoirs become functions of random variables.

The simplest way of describing a random variable is through its mean value and standard deviation, without indicating the type of probabilistic distribution that describes it. When statistical data are available, a standard uncertainty $\left(u_{x_{i}}\right)$ of a variable/parameter $\left(x_{i}\right)$ is defined as the statistically determined standard deviation of the repeated measurements (experiments). 
When statistical data are not available, the standard uncertainty is defined as limits within which the true value of the parameter is expected to lie. However, many real situations cannot be tested, and estimations have to be done by comparisons with similar or well studied cases.

In order to obtain a combined standard uncertainty for an equation, and so for the output variable, a simple procedure is described. Given an output $y$ that is a function of $n$ inputs:

$$
y=y\left(x_{1}, x_{2}, x_{3}, \ldots, x_{n}\right)
$$

the sensitive coefficient of $y$ to $x_{i}\left(S_{x_{i}}\right)$ is obtained as follows:

1. Determine two values $x_{i}$ that are slightly more and less than the nominal value of $x_{i}$. These are called $x_{i}^{+}$and $x_{i}^{-}$;

2. Calculate values of y using $x_{i}^{+}$and $x_{i}^{-}$. These are called $y^{+}$and $y^{-}$, respectively;

3. Define $\Delta x=x_{i}^{+}-x_{i}^{-}$and $\Delta y=y^{+}-y^{-}$. The sensitivity coefficient is then calculated by:

$$
S_{x_{i}}=\left(\frac{\Delta y}{\Delta x_{i}}\right) \times\left(\frac{x_{i}}{y}\right)
$$

Once all the standard uncertainties $\left(u_{x_{i}}\right)$ and sensitivity coefficients $\left(S_{x_{i}}\right)$ are known for all variables, the combined uncertainty is then calculated by:

$$
\frac{u_{y}}{y}=\sqrt{\sum_{i=1}^{n}\left(S_{x} \times u_{x}\right)_{i}^{2}}
$$

The ratio of value $100 \times\left(S_{x} \times u_{x}\right)_{i}^{2}$ for each variable $x_{i}$ to the total $\sum_{i=1}^{n}\left(S_{x} \times u_{x}\right)_{i}^{2} \quad$ represents the percentage of the total uncertainty that can be attributed to the parameter $x_{i}$.

These values are on the ability to make decisions on the uncertainty analysis data. Supposing that a decision is to be taken on where to focus efforts or to implement mitigation measures, this analysis helps us to reduce the overall uncertainty to an acceptable value.

An uncertainty analysis provides two types of information: first it calculates the relative importance of the uncertainty of each input parameter in the uncertainty of the global results of the model; second, it calculates the global uncertainty of the model as a function of the uncertainties of each input parameter. 


\section{Safety philosophy}

Potential risks for a dam-reservoir system can be provoked by different hazards (underestimation of the design floods, underestimation of the catastrophic landslide effects, underestimation of the design earthquake loads, underestimation of the spillway capacity, inadequate analysis of structural stability, operation errors, acts of war, or sabotage).

All these causes can induce a potential threat to the downstream-valley system including the river, the land and the people with its social organisation and infrastructures. For each potential event or hazard $E_{i}$ acting on the damreservoir system, the formal mathematical risk, $R_{i}$, can be considered splitted into two kinds of risk: the internal dam risk and the external or downstream valley risk. As shown in [3], equation (4) presents this formal risk concept:

$$
R_{i}=\underbrace{P\left(E_{i}\right)}_{\begin{array}{c}
\text { Hazard } \\
\text { probability }
\end{array}} \int_{0}^{N_{M a x}} \int_{0}^{Q_{M a x}} P \underbrace{\left(Q_{p} \mid E_{i}\right)}_{\begin{array}{c}
\text { Internal risk } \\
\text { reduction }
\end{array}} P \underbrace{\left(N \mid Q_{p}\right)}_{\begin{array}{c}
\text { External risk } \\
\text { reduction and } \\
\text { responses }
\end{array}} N d N d Q
$$

where $P\left(E_{i}\right)=$ event or hazard occurrence probability, $P\left(Q_{P} \mid E_{i}\right)=$ conditional probability of occurrence of a hazard with maximum disturbance $Q_{P}$ induced by the dam response to event $E_{i}$ and $P\left(N \mid Q_{P}\right)=$ conditional probability of $N$ losses along the valley due to the induced dam-break disturbance.

Sustainable valley development is achieved if integrated valley management considers environmental safety and vulnerability, as well as economic and ethical aspects. With this regard, a vulnerability index $\left(I_{V}\right)$ is proposed in [3], as a function of two main factors: agressivity or fluid physical factor $\left(I_{P V}\right)$, related to the physical characteristics of the flood induced by the reference failure scenario, and the fragility factor $\left(I_{S V}\right)$, related to the social, economic and environmental characteristics of the valley. For each valley sub-zone $j$, the proposed index is defined by $I_{V, J}=I_{P V, J} \times I_{S V, J}$. The global valley vulnerability $\left(I_{V V}\right)$ can be obtained by a weighted sum based on the distance of each sub-zone to the upstream dam.

In this same context, an integrated dam-reservoir-valley risk management system can be conceptually composed by two parts: the risk assessment process, in which an approximate quantitative risk analysis and evaluation is made, and the risk mitigation process, in which actions to reduce the risk are identified and implemented.

The ultimate objective of disaster management is to bring the probability that damage will occur from an event as close to zero as is possible. This requires an understanding of all of the elements contributing to a disaster. In case of a damreservoir system, these elements include:

1. Hazards and risks dictated by nature (e.g., earthquakes, floods, landslides, etc); 
2. Hazards and risks introduced by humans in order to achieve another objective (e.g., a dam for hydro-electrical power, flood control, irrigation, water supply, etc);

3. Actions of humans that result in augmentation of the negative effects of an event (e.g., cutting trees for heating or for building materials or for agricultural purposes, thereby increasing the risks for erosion, landslides, or flooding; improvements in riverbeds in an effort to prevent flooding upstream that may worsen flooding downstream, etc); and/or

4. Acceptance of a calculated risk (e.g., valleys, flood plains, shorelines, thereby increasing exposure to floods; or in an earthquake-prone area, etc).

\section{Hazard and risk assessment}

A fundamental condition for disaster preparedness is the availability of risk assessments and well-functioning early warning systems that deliver accurate and useful information in a timely and dependable manner to decision-makers and the population at risk. While natural hazards may not be avoided, integration of risk assessment and early warnings, together with prevention and mitigation measures, can prevent them from becoming natural disasters.

Risk management has always been practised. In its simplest form it comprises decision making based on whatever knowledge or skills may be possessed. Recent advances in computers mean that now it is possible to quickly access a range of information that may include:

- real time performance of a dam-reservoir including rainfall, flow, etc;

- monitoring data;

- dam-break modelling data for various scenarios - inundation plans, etc;

- GIS systems including information on inundation, land use, centres of population, valley infrastructure, etc;

- simulation/expert systems for guidance on what if scenarios;

- historical data on flooding, dam incidents, and dam maintenance.

It is becoming widely recognised that efficient monitoring and warning systems are vital for the effective identification and management of key risks. Indeed better design criteria have been developed and safer dams are being built, but there is no basis for complacency. Dams continue to age, people continue to move into inundation zones and enough hazards exist that the net risk to the public will remain high for many years. Risk management includes risk control and mitigation in order to avoid an increase of risk with the time.

In accordance with [4], the entire risk assessment comprises three equal parts: risk analysis, risk evaluation and risk management.

Risk analysis is a quantitative method that seeks to determine the outcome of a decision situation as a probability distribution. It is mostly approached using methods based on engineering and natural science. The risk evaluation should be connected to appropriate risk tolerance criteria depending on the associated social, environmental, and economic consequences, in order to establish measures and actions for risk mitigation and risk management. Risk management 
combines the results of risk analysis and risk evaluation to find the "best" solution. Figure 1 displays the overall risk assessment process, comprising a risk analysis and a risk calculation (estimation and evaluation). A perfect quantitative comparison between available and admissible (tolerable) risks according to this figure should be intended. The questions presented are characterising the main focus of each part.

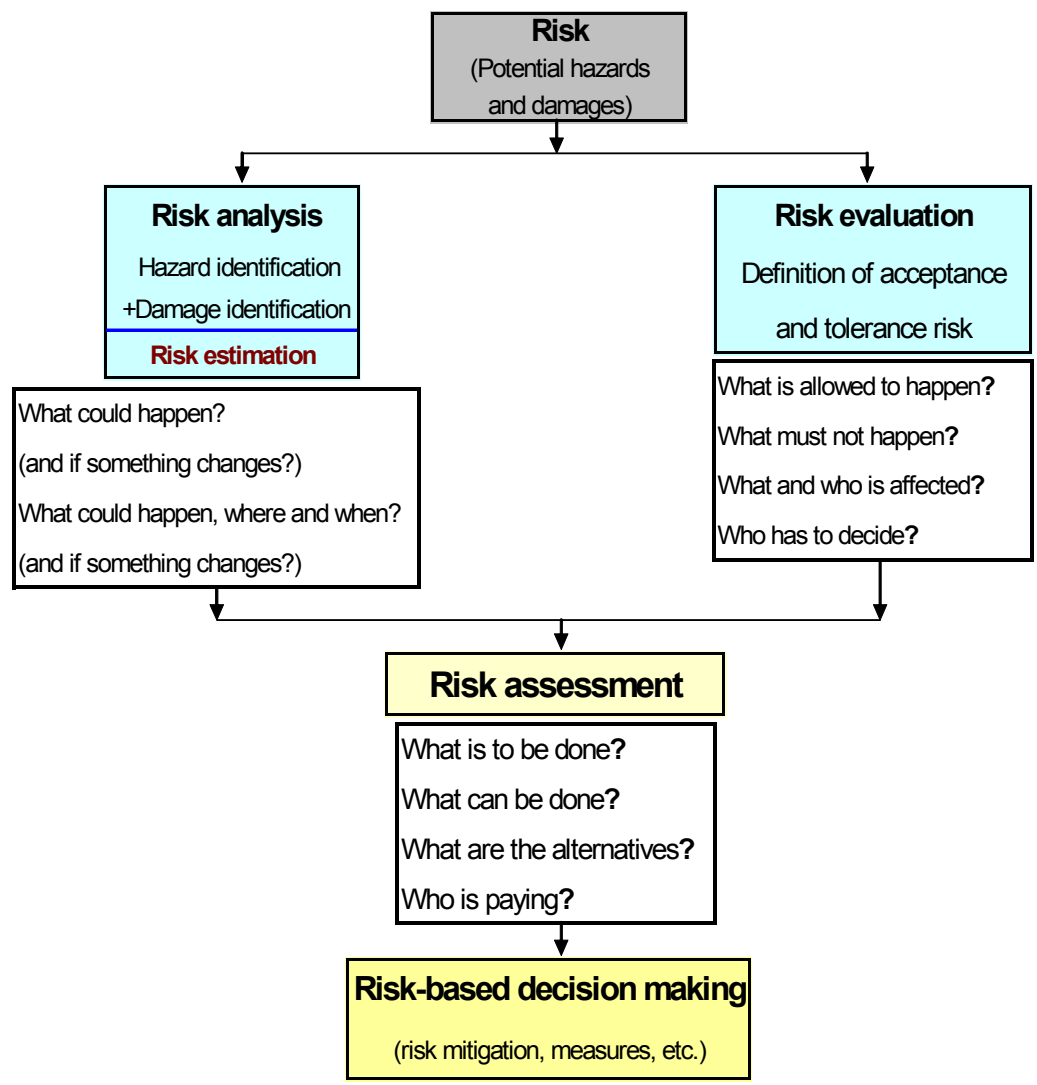

Figure 1: $\quad$ Risk assessment process (from [4] and [5]).

Strictly speaking, there are two risks or probabilities associated with the presence of a hazard: (1) the risk that a hazard will become an event (or a probability that a hazard will turn into an event, occurrence of an extreme flow, an earthquake or a landslide); and (2) the risk that damage will occur, or damage probability (dam-break or dam overtopping). A disaster, then, is a possible result of a hazard that becomes an event and produces damage for people that are living in the area and/or are dependent on the existing economic resources.

Therefore, identification of the elements that may define the probability that an actuated hazard will create damage is helpful for decision-making such as what to do, when to do, and how to do, to guarantee the maximum safety for 
infrastructures and people at risk. The event, in itself, may or may not produce enough damage to create a disaster. This is dependent heavily upon the extent to which a society is vulnerable to the occurrence of a specific event. Both the features of nature and the influence of human actions determine this vulnerability.

\section{Vulnerability assessment}

In any risk management system it is necessary to determine the potential impact of different scenarios. Determining the impact of catastrophic flooding, resulting from a dam-break, is a subjective process since there is little direct guidance available on many of the key issues. These issues include:

- Societal Response to Flooding and Flood Warning (Risk Perception)

It has been recognised that the response of a population during an emergency depends upon a number of factors including their perception of the threat (proximity to dam), and prior knowledge of the emergency warning system.

- Vulnerability of Society to Flood Impact and Estimation of Potential Loss of Life

The vulnerability of society to flood impact depends upon their age, location, education, etc. The estimation of potential loss of life depends upon a range of factors but most importantly location with respect to the dam and period of warning time given prior to flood impact. If a reliable estimate of potential loss of life can be calculated, what is an acceptable risk to life?

- Flood Impact on Structures and Infrastructure

When trying to determine the impact and/or economic impact of flooding it is necessary to determine the degree of damage that may be caused by the flood flow. This in turn requires an understanding of loading and local scour conditions under which structures are likely to fail (i.e. under what flow conditions would a house collapse?). As construction techniques and typical buildings vary widely across any country, damage curves will be required for each region/area.

\section{- Environmental Impact of Flooding}

Methods for determining impact on the environment from flooding are limited. A possible approach is to establish a relative ranking of impact from multiple sites. Reliable techniques for the assessment of financial impact are not yet developed.

According to [6], a conceptual procedure for vulnerability assessment can be schematically represented by the following flow chart (Figure 2), where the direct vulnerability (V), excluding vulnerability of people, is assessed by comparing the value of damage (loss of the element due to a hazard of a given type and magnitude) with the actual value of the element at risk, i.e,

$$
\text { Vuln erability, } \mathrm{V}=\frac{\text { Losses, or value of damage }(€)}{\text { Value, or construction } \cos t(€)}
$$




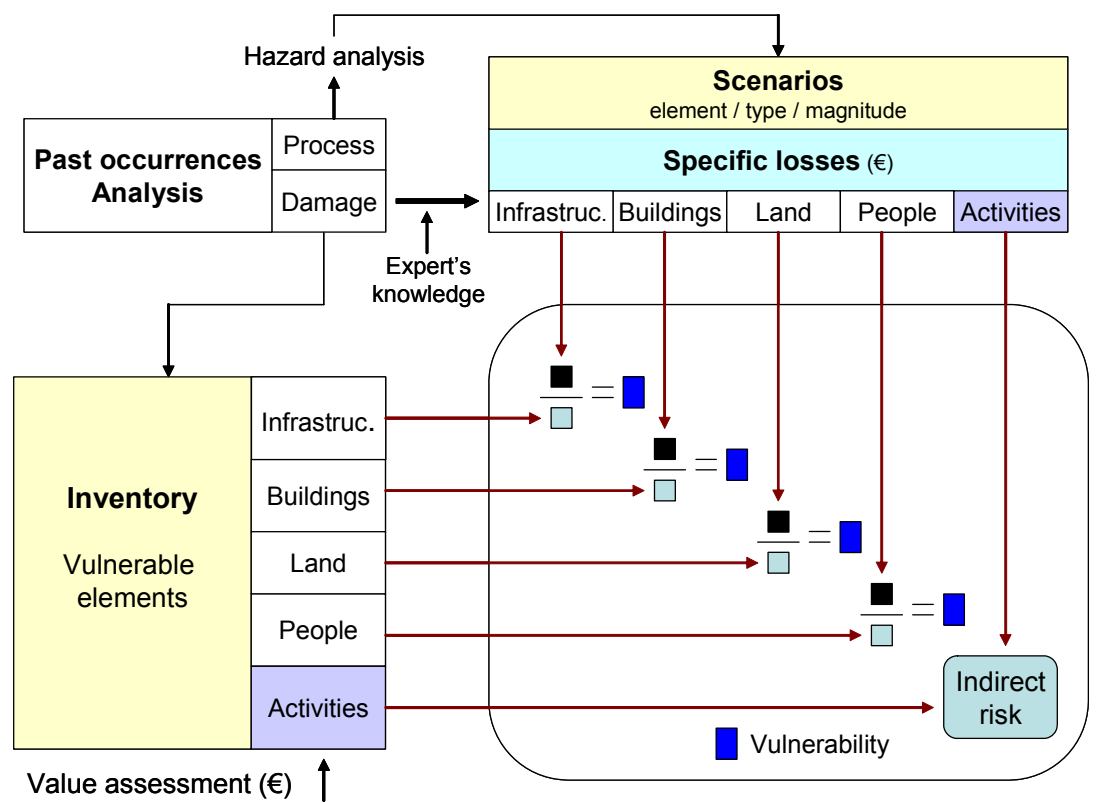

Figure 2: $\quad$ Conceptual procedure for vulnerability assessment (from [6]).

\section{Hazard and risk analysis}

\section{- Direct risk modelling}

Once maps of hazard, vulnerability and value were created for different elements at risk, they are combined in a direct risk map using the expression (5):

$$
R_{D}=H \times E \times V
$$

where $R_{D}$ - direct risk ( $€ / R P$ year); $H$ - hazard events $(0-1 / \mathrm{RP}$ year) $(R P=$ Return period, usually 50 years); $E$ - elements values $(€)$, and $V$ - vulnerabilities $(0-1)$ created for all elements at risk.

Risk values thus obtained are equivalent to specific losses multiplied directly by the hazard. Mapping is carried out separately for each type of element (specific risk) and then combined into a map of total risk by adding all maps of specific risk. A complete view of the risk for a given element should integrate multiple scenarios of hazards and vulnerability values for the different types of occurrences and their magnitude.

\section{- Indirect risk modelling}

When a hazardous event takes place, damage to material elements has an indirect effect by disrupting socio-economic activities. In general, indirect effects 
mainly originate in damage to infrastructure and may affect a wide area, even far from the study area. As pointed out by [6], the concept of indirect damage (resulting form indirect disruption of non-material elements) is fuzzy and difficult to assess. A possible approach is to estimate potential losses indirectly due to the occurrence of damaging phenomena of a given magnitude that affect economic activity.

- Total risk

Total risk $\left(R_{T}\right)$ is the sum of the direct risks $\left(R_{D}\right)$ and the indirect effects on socio-economic activities $\left(R_{I}\right): R_{T}=R_{D}+R_{I}$.

\section{Risk mitigation process}

In valleys and flood plains downstream dams the engineering paradigm based in structural defences against floods can not be considered due to the abnormal dam-break flood characteristics. Non-structural alternatives, such as land zoning, dam monitoring and hazard forecasting, warning and evacuation planning as well as the consideration of the behaviour of those involved (managers and residents) in the floodplain emergency planning need to be implemented. So in this aspect of floodplain safety and risk management we need to consider the following strategies:

- The principle of preventing accidents, in what concerns the internal risk reduction management (in dam operation).

- The principle of minimizing damage, in what concerns the external risk reduction management (in valley management).

Following [3] and [5], a 'safety philosophy' for dam-reservoir and valley systems can be represented, in a very simplified manner, as shown in Figure 3.

\section{Methodology for management of accidents}

To enable a decrease in the number of accidents that occur, as well as preparing to cope with the consequences of the accidents, society has to work systematically with risk management and civil protection. Accidental risks have to be identified, analysed and evaluated, and actions, contributing to improvement of society's protection against accidents, have to be taken. Civil protection also includes effective management of accidents that do occur in spite of preventive actions (see Figure 4, from [7]). Environmental risks have to be incorporated into both accident risk management and civil protection in the municipalities. In general, management of accidents is mainly performed at local level, which makes the municipality an important actor in this process. Moreover, the municipalities often have to deal with the consequences of accidents, and hence have strong incentives to work with these issues. 


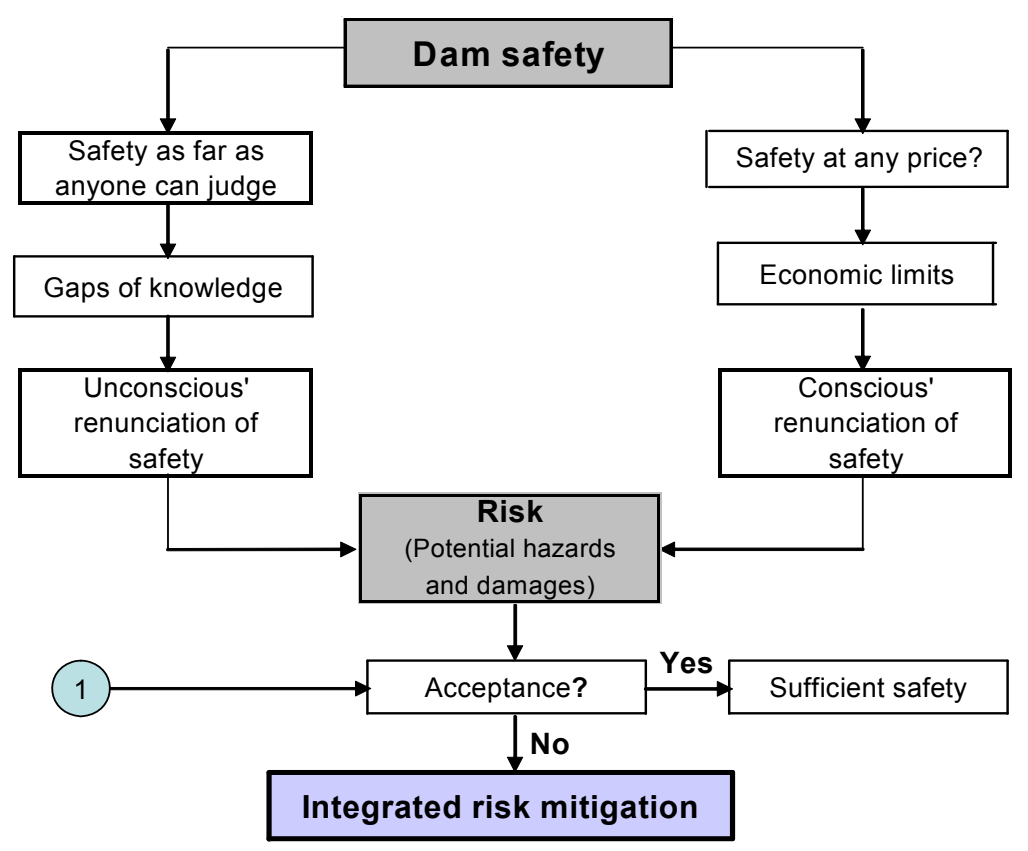

a)

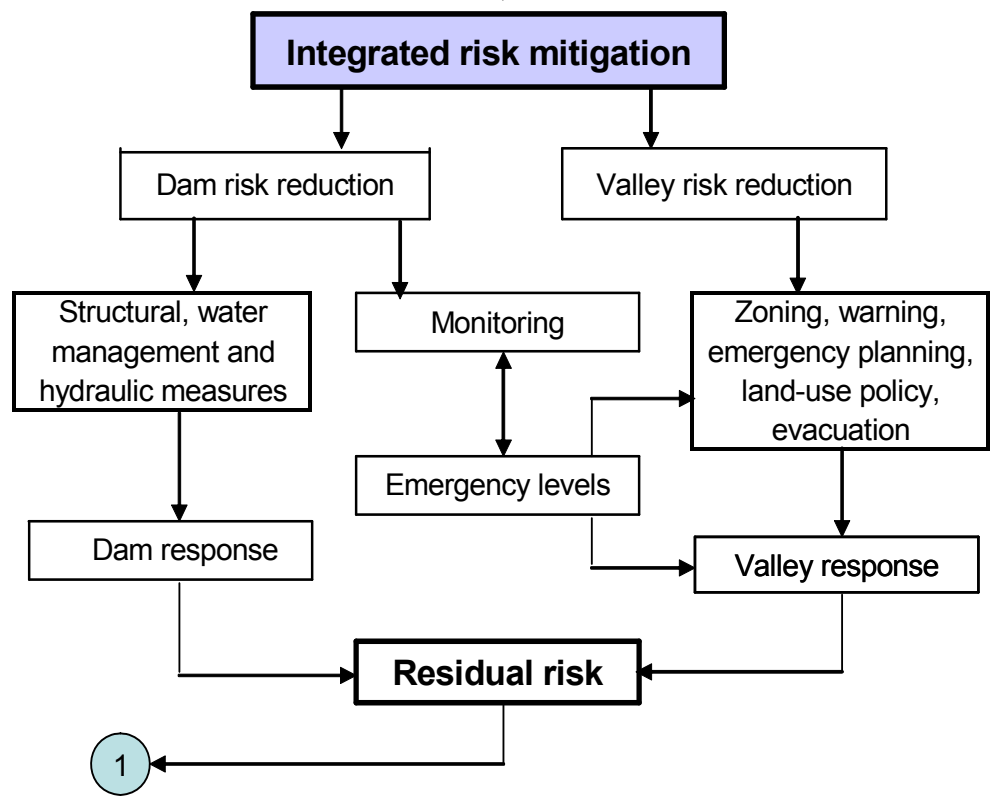

b)

Figure 3: Philosophy of dam-reservoir and valley systems safety: a) Dam 'safety philosophy'; b) Integrated risk mitigation phase, as part of the dam 'safety philosophy'. 


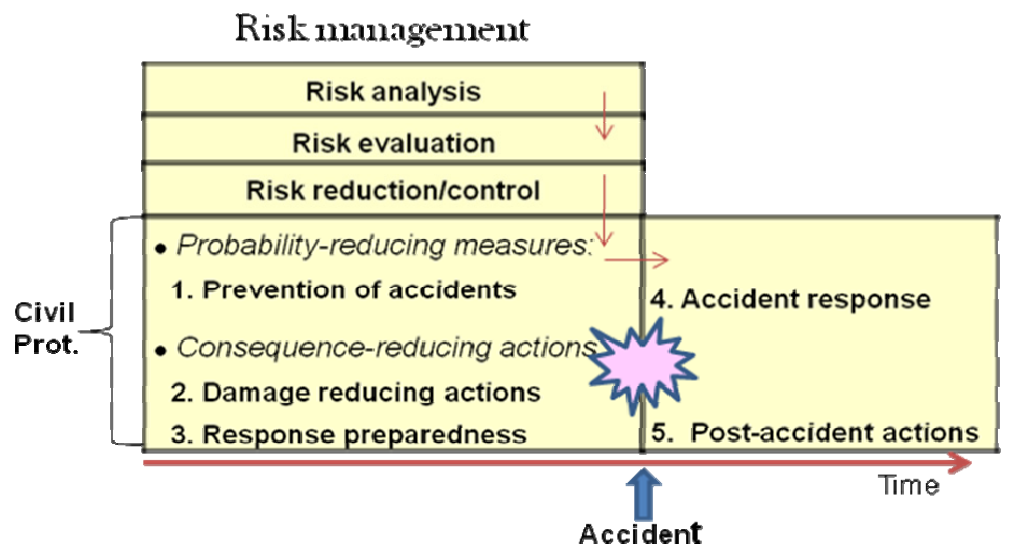

Figure 4: Methodology for management of accidents combining risk management (vertically) and civil protection (horizontally) [7].

\section{Conclusions}

A number of rules should be kept in mind for systematizing and preparing guidelines to help in the design, construction and operation of large damreservoir systems, as well as for emergency planning and risk management procedures for both dam owners and civil defence authorities. As a first approach, an integrated methodology is adopted for the study of dam-reservoir and valley systems in the context of risk analysis. A safety philosophy is proposed, and conceptual procedures for uncertainty modeling and vulnerability assessment are presented. Finally, and in a very simplified manner, a conceptual risk mitigation process for dam-reservoir and valley systems is shown.

\section{References}

[1] Almeida A.B., Ramos C.M., Santos N.A. and Viseu T., 2003. Dam-break flood risk management in Portugal. ISBN 972-49-1979-X.

[2] Singh V.P., 1996. Dam Break Modelling Technology. Kluwer Academic Publishers, Dordrecht.

[3] Almeida A.B., 1999. Dam Risk Management at Downstream Valleys. Proc. $3^{\text {rd }}$ CADAM Workshop. Eds.: G. Testa, M. Morris \& K. Fabbri.

[4] Bell R. and Glade T., 2004. Quantitative risk analysis for landslides.... Natural Hazards and Earth System Sciences, 4: 117-131.

[5] Sieber H.-U., 2002. Hazard and risk assessment considerations... (http://www.talsperrenkomitee.de/german_research/index.cgi)

[6] Remondo J., Bonachea J. and Cendrero A., 2008. Quantitative landslide risk assessment and mapping... Geomorphology, 94, 496-507.

[7] Kjellberg N. and Sandström C., 2007. Master of Science in risk management and safety engineering at Lund University. Ed.: R. Jönsson, 153-154. 